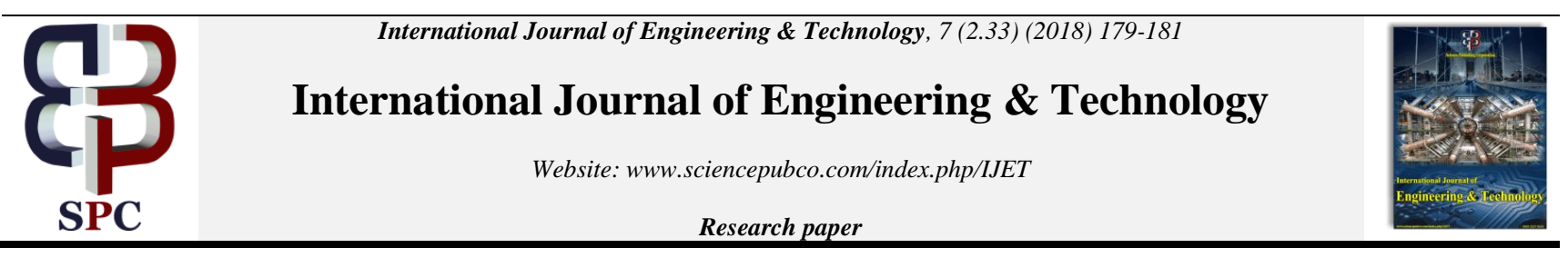

\title{
Study on force characteristics in accordance with gear ratio of the linear magnetic gear
}

\author{
Sung-Won Seo ${ }^{1}$, Kyung-Hun Shin ${ }^{1}$, Keyyong Hong ${ }^{2}$, Kyong-Hwan Kim ${ }^{2}$, Jang-Young Choi ${ }^{1}$, \\ ${ }^{1}$ Department of Electrical Engineering, Chung-nam National University, 99, Dae-hak-ro, Yusung-gu, Daejeon, 34134, Korea \\ ${ }^{2}$ Offshore Plant Research Division, Korea Research Institute of Ships \& Ocean Engineering, Daejeon 305-343, Korea \\ *Corresponding author E-mail: choi_jy@cnu.ac.kr
}

\begin{abstract}
We have studied linear magnetic gears. Since linear magnetic gears are excellent in terms of ease of manufacture and economy, we studied linear magnetic gears in this paper. The speed and the force of the secondary side of the magnetic gear are determined according to the gear ratio. In additional, the linear magnetic gear also performs a linear reciprocating motion different from the rotary magnetic gear. Therefore, in this paper, the model selection was made through reference works. The selected models had analyzed in accordance with gear ratio.Especially, the characteristics analysis method was compared with total harmonic distortion and force ripple. Also, it is possible to predict and compare the total harmonic distortion, the force ripple, and the speed according to the gear ratio. Finally, the speed comparison between the primary side and the secondary side of the gear ratio was carried out and the validity of the research direction of the linear gear was verified through all the results. All results are important for predicting gear ratio selection of precision linear magnetic gears. Therefore, in this paper, the load force is set opposite to the secondary side, and through this process to obtain accurate results from the analysis of the linear magnetic gear. From the analysis results of this paper, we can analyze the combined model of linear magnetic gear and linear generator.
\end{abstract}

Keywords: Force Characteristic; Gear Ratio; Linear Magnetic Gear; Total Harmonic Distortion; Two-Dimensional Finite Element Analysis.

\section{Introduction}

Anelectric machine cannot independently deliver power and depend upon gears to deliver this power source. These gears consist of toothed wheels where the wheels deliver power to a mechanical system by utilizing teeth on both the primary and secondary gear. These gears are used in a variety of mechanical systems that are run at both low and high speeds (D. E. Hesmondhalghand D. Tipping, 1980; K. Tsurumoto and S. Kikushi., 1987; K. Ikuta et al., 1991). Generally, these systems span wind power generators, automobile systems, and household appliances (K. Atallah and D. Howe, 2001). While gears deliver power, they are not without their limitations. Gears use metal materials and cause mechanical losses. Specifically, when gears experience extreme temperatures at high speed rotation, the gear teeth are weakened causing abrasion, friction loss, vibration, and noise. Additionally, gears can be very maintenance heavy requiring constant maintenance to operate. This being said, magnetic gears can effectively compensate for the disadvantages over conventional gears (M. Chenet al., 2014; P. O. Rasmussenet al., 2005). The mechanical loss of the magnetic teeth can be minimized by using permanent magnets, which also reduces the constant need for maintenance. Furthermore, it is possible to reduce the overall size and weight. This is based upon a high energy density due to the discovery of a rare earth magnetic substance. Additionally, it is possible to reduce manufacturing costs throughout the manufacturing process. For these reasons, a variety of research has been conducted focusing on the use of magnetic gears when leveraging permanent magnets. In particular, the focus of past research has been on rotary gears. However, in a linear motion system, such as wave power genera- tion, utilizing a linear gear is inevitable (K. Atallah et al., 2006; C. T. Liu et al., 2016). For this reason, research on magnetic gears of tubular structure has recently been conducted, but difficulties in manufacturing and high cost are noted as key limitations. A similar result can be obtained by simplifying the tubular structure to a linear structure (L. Wanget al., 2014).

In this paper, we analyzed the force characteristics of linear magnetic gears using permanent magnets according to gear ratio. First, the model selection was determined by referring to reference ( $\mathrm{L}$. Wanget al., 2014), and the analysis was carried out by adjusting the gear ratio of the secondary side accordingly. An analysis of the Total Harmonic Distortion (THD) was performed after obtaining the pull-out force of each gear ratio (N. Yousefpooret al., 2012). Next, the magnitude, torque ripple, and speed of the force obtained from the transient analysis were calculated. 


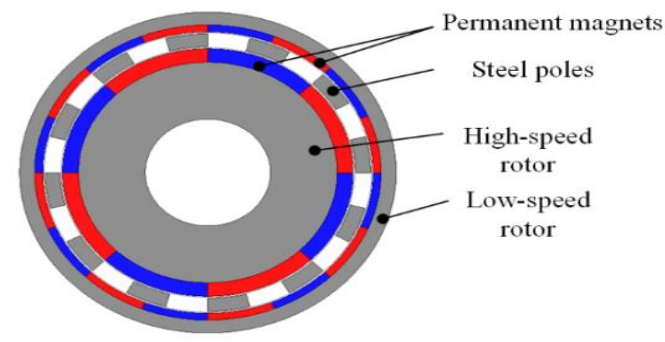

Structure of co-axial magnetic gear

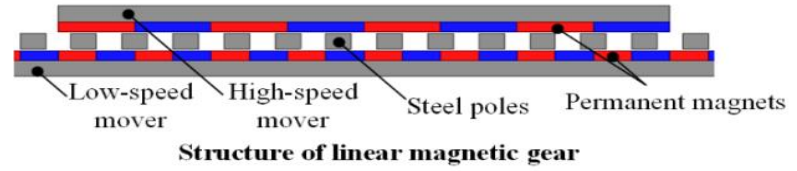

Fig. 1: Structure of Linear Permanent Magnet Gears.

Table 1: Parameters of the Analyzed Linear Permanent Magnet Gear

\begin{tabular}{ll}
\hline Parameter & Values \\
\hline Thickness of primary mover [mm] & 8 \\
Thickness of secondary mover [mm] & 5 \\
Thickness of steel pole [mm] & 6 \\
PM thickness on primary mover [mm] & 5 \\
PM thickness on secondary mover [mm] & 2.5 \\
Number of pole-pairs on primary mover & 8 \\
Number of pole-pairs on secondary mover & $32 \sim 44$ \\
Length of each air-gap [mm] & 1 \\
Stack length [mm] & 10 \\
\hline
\end{tabular}

Lastly, the amount of error, characteristics of the gears, and calculated values were compared with each gear ratio for a final assessment. All analytical processes were performed using the twodimensional (2-D) finite element analysis method.

\section{Structure and analysis method of linear magnetic gears}

In this paper, we analyzed the study on force characteristics of according to the gear ratio by fixing the high-speed mover of the linear magnetic gear to 8 poles and changing the number of poles of the low-speed mover using a 2-D finite element analysis method. In addition, we conducted transient analyses of the force and force ripple of the linear magnetic gears and the mover speed of the low-speed mover for various ratios. We analyzed a total of 8 gear ratios. First, the gear ratios were divided into integer and noninteger ratios. Then, characteristic analyses were performed for non-integer gear ratios of half and quarter.

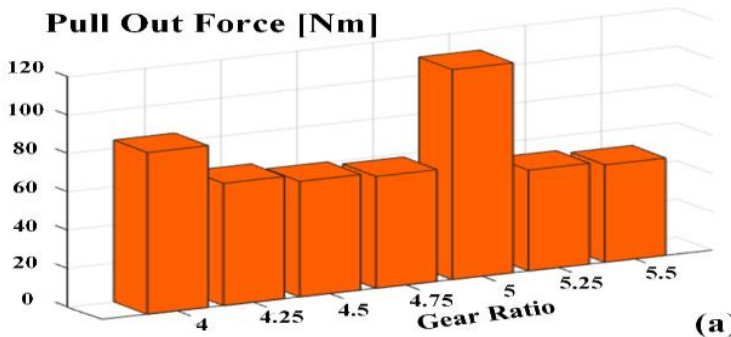

(a)

THD [\%]

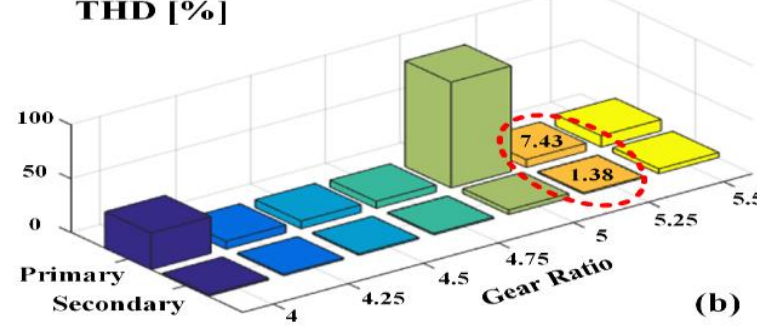

Fig. 2: Analysis Result According to Gear Ratio: (A) Pull-Out Force, (B) THD.

\section{Selection of analysis model}

The linear magnetic gears studied in this paper are shown in Fig. 1. The magnetic gear has a structure similar to the magnetic coupling but has steel poles between the drives on both sides. This supports the principle that both sides of the rotor system are modulated by steel poles and driven in the opposite direction of the driver. Figure 1 shows a rotating magnetic gear as well as a linear magnetic gear. The high-speed mover and low-speed mover in the linear magnetic gear are referred to as primary and secondary, respectively throughout the rest of this paper. As with rotating magnetic gears, the number of poles on the primary side is fixed at eight, and when moving at a maximum speed of $1 \mathrm{~m} / \mathrm{s}$, the speed of the secondary side moves in the opposite direction. Since the selection of the gear ratio is based on reference 4 , the gear ratio ranges from 4 to 5.5 based upon the gear ratio at that time. In general, motion of the rotating magnetic gear are opposite in direction to the primary. On the other hand, linear magnetic gears must reciprocate motion due to the limit of the length of the linear magnetic gear. Therefore, in this paper, we analyzed the reciprocating motion as well as the unidirectional motion. Particularly, in order to see the section where the force converges when moving in one direction, the overall length of the secondary side is lengthened and the analysis is proceeded. The parameters of the analytical model are noted below in Table I. Linear magnetic gears must

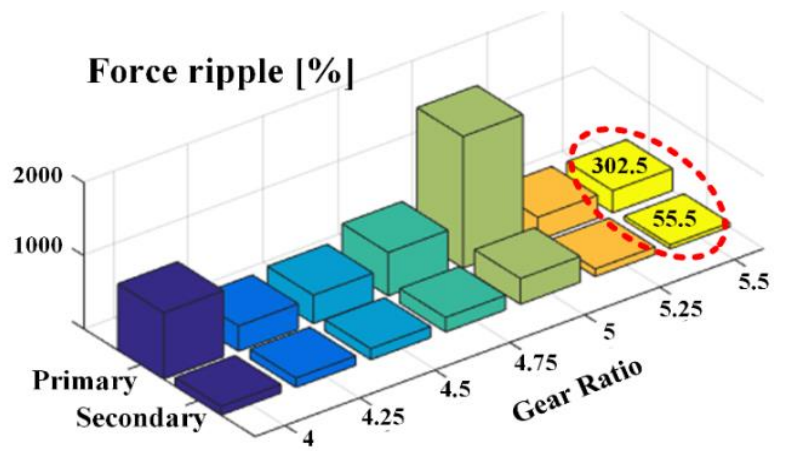

Fig. 3: Force Ripple Analysis Result According to Gear Ratio.

Accurately calculate the mass when considering the movement according to the gear ratio. The number of steel poles can be obtained by $\mathrm{N}_{\mathrm{s}}=\mathrm{p}_{1}+\mathrm{p}_{2}$, and the mover speed and gear ratio can be obtained from equation (1) and equation (2) as noted below (L. Wanget al., 2014).

$\omega_{1}=-G_{r} \omega_{2}$

$G_{r}=\frac{p_{1}}{p_{2}}$

Wherep 1 and $\mathrm{p}_{2}$ are the number of primary poles and secondary poles, $\omega_{1}, \omega_{2}$ and $G_{r}$ refer to the primary speed, secondary speed, and gear ratios. Also, the negative sign indicates the directions of the primary and secondary sides are opposite to one other.

\section{Pull out force analysis and THD analysis}

Pull-out force is only obtained when the primary side speed is given; not the secondary side. The value is determined by predicting the maximum force the magnetic gear can produce and is the most important analysis in the initial design process of the magnetic gear. The results of the gear ratio increased along with an a substantial increase in the pull-out force are shown in Fig. 2 (a). When the gear ratio is a non-integer; the pull-out force decreases steadily. Figure 2 (b) shows the result of the THD analysis and the corresponding equation to determine THD is found in (3). 


$$
T H D=\left(\frac{\sqrt{F_{2}^{2}+F_{3}^{2}+\cdots+F_{n}^{2}}}{F_{1}}\right) \times 100
$$

Here, $F_{n}$ denotes the $n$-th harmonic component of one iteration of the pull-out force of each gear ratio. Figure 3 shows the result of force ripple transient analysis according to gear ratio. The force ripple can be obtained by utilizing equation (4).

$$
\frac{F_{\max }-F_{\min }}{F_{\text {avg }}} \times 100
$$

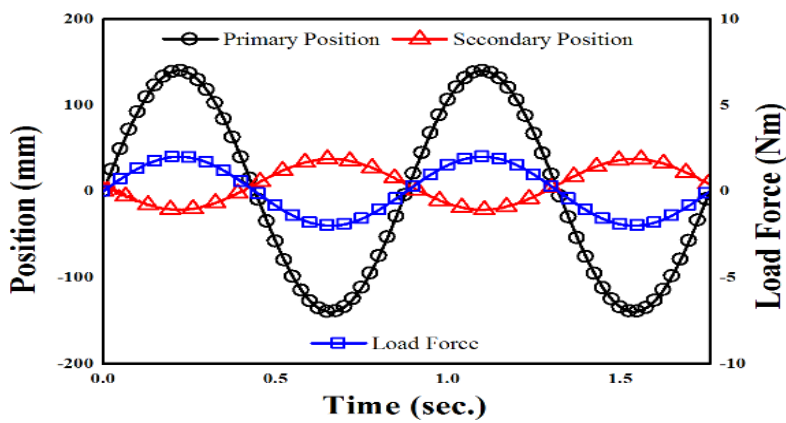

Fig. 4: Load Force According to Position in Transient Analysis.

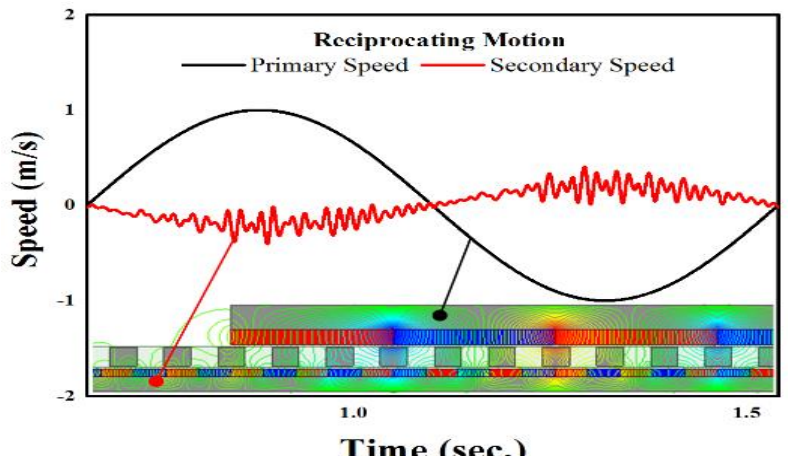

Fig. 5: The Reciprocating Motion of the Secondary Side and the Flux Line.

$\mathrm{F}$ in equation (5) represents the force according to the gear ratio. These results were obtained by leveraging the results of the steady state analysis as mentioned above. Specifically, it refers to the result of the convergence section when the velocity is $1 \mathrm{~m} / \mathrm{s}$. However, in applications where actual linear magnetic gears are used, there is a limit in the finite element analysis in the steady state due to the reciprocating motion of the primary side is required. Therefore, Fig. 4 demonstrates the load force according to the position of the primary and secondary sides in the linear reciprocating motion from the transient analysis. This means that when the primary and secondary move in opposite directions, the load force on the primary side is applied in the opposite direction of the secondary side. If there is an infinite motion in one direction, such as a rotary, the load force may take into account only integer values that are opposite to the secondary. In the case of linear reciprocating motion, however, the sinusoidal function should be considered in the load force. Figure 5 shows the operating speeds of the primary and secondary mover. From both Figs 4 and 5, one can see that each gear moves in the opposite direction during the reciprocating motion; at a speed determined by the gear ratio at that time. In addition, Table II and Table III shows the analysis results for the secondary speed and force of each gear ratio with respect to the primary side $1 \mathrm{~m} / \mathrm{s}$ speed and force. Here, Ideal values can be calculated using Equation (1). Therefore, it can be confirmed that the FEA result and the ideal value match very well and it shows the reliability of the analysis results.
Table 2: Speed Results According to Gear Ratio

\begin{tabular}{llll}
\hline Ratio & FEA & Ideal Speed & Error \\
\hline 4 & $0.249[\mathrm{~m} / \mathrm{s}]$ & $0.25[\mathrm{~m} / \mathrm{s}]$ & $0.48[\%]$ \\
4.25 & $0.233[\mathrm{~m} / \mathrm{s}]$ & $0.235[\mathrm{~m} / \mathrm{s}]$ & $1.15[\%]$ \\
4.5 & $0.222[\mathrm{~m} / \mathrm{s}]$ & $0.222[\mathrm{~m} / \mathrm{s}]$ & $0.33[\%]$ \\
4.75 & $0.21[\mathrm{~m} / \mathrm{s}]$ & $0.211[\mathrm{~m} / \mathrm{s}]$ & $0.25[\%]$ \\
5 & $0.201[\mathrm{~m} / \mathrm{s}]$ & $0.2[\mathrm{~m} / \mathrm{s}]$ & $0.45[\%]$ \\
5.25 & $0.186[\mathrm{~m} / \mathrm{s}]$ & $0.190[\mathrm{~m} / \mathrm{s}]$ & $2.35[\%]$ \\
5.5 & $0.182[\mathrm{~m} / \mathrm{s}]$ & $0.182[\mathrm{~m} / \mathrm{s}]$ & $0.01[\%]$ \\
\hline
\end{tabular}

Table 3: Force Results According to Gear Ratio

\begin{tabular}{llll}
\hline Ratio & FEA & Ideal Force & Error \\
\hline 4 & $24.9[\mathrm{Nm}]$ & $26[\mathrm{Nm}]$ & $4.22[\%]$ \\
4.25 & $24.71[\mathrm{Nm}]$ & $24.94[\mathrm{Nm}]$ & $0.93[\%]$ \\
4.5 & $24.33[\mathrm{Nm}]$ & $23.23[\mathrm{Nm}]$ & $4.76[\%]$ \\
4.75 & $24.18[\mathrm{Nm}]$ & $22.99[\mathrm{Nm}]$ & $5.2[\%]$ \\
5 & $24.36[\mathrm{Nm}]$ & $24.93[\mathrm{Nm}]$ & $2.3[\%]$ \\
5.25 & $23.85[\mathrm{Nm}]$ & $24.11[\mathrm{Nm}]$ & $1.06[\%]$ \\
5.5 & $23.78[\mathrm{Nm}]$ & $24.43[\mathrm{Nm}]$ & $2.66[\%]$ \\
\hline
\end{tabular}

\section{Conclusion}

In this paper, we analyzed force characteristics according to the ratios of linear magnetic gears. Based upon the characteristics of rotary type magnetic gears, as noted through previous studies, we then applied said characteristics to linear magnetic gears. In terms of gear ratios, the results were similar. Further analysis was also conducted on the reciprocating movement and its effects on a linear magnetic gear. As such, the results of this paper will be used in a mechanical system requiring linear motion.

\section{Acknowledgment}

This work was supported by the Basic Research Laboratory (BRL) of the National Research Foundation (NRF-2017R1A4A1015744) funded by the Korean government.

This research was supported by a grant from National R\&D Project of "Development of Wave Energy Converters Applicable to Breakwater and Connected to Micro-Grid with Energy Storage System" funded by Ministry of Oceans and Fisheries, Korea (PMS3780).

\section{References}

[1] Atallah,K., Howe,D.,2001, A novel high performance magnetic gear. IEEE Trans onMagn, 37(4): 2844-2846.

[2] Atallah,K., Wang,J.,\&Howe,D., 2006, A high-performance linear magnetic gear. Journal of Appl. Phys, 97: 10N516-1-10N516-3.

[3] Chen,M., Chau,K. T. Li,W., Liu,C.,\&Qiu,C.,2014, Design and analysis of a new magnetic gear with multiple gear ratios. IEEE Trans. Appl. Supercond, 24(3): 1167-1170.

[4] Hesmondhalgh, D. E., Tipping, D., 1980, A multielement magnetic gear. IEE Proceedings, 127(3): 129-138.

[5] K.Ikuta, S.Makita, S.Arimoto, 1991, Non-contact magnetic gear for micro transmission mechanism. Proc. IEEE Conf. Micro Electro Mechanical Systems, 125-130.

[6] Liu,C. T., Hung, K. Y., \& Hwang, C. C., 2016. Developments of an efficient analytical scheme for optimal composition designs of tubular linear magnetic-geared machines. IEEE Trans on Magn, 52(7): 82024041-4

[7] L.Wang, M.Jin, J.Shen, Z.Huang, \&J.Wang, 2014, Design of a High-Performance Linear Permanent Magnet Gear. ICEMS 2014: 2324-2326.

[8] Rasmussen, P. O., Andersen, T. O., Jørgensen,F. T., \& Nielsen, O. 2005,Development of a high-performance magnetic gear. IEEE Trans. Ind. Appl., 41 (3): 764-770.

[9] Tsurumoto, K., Kikushi, S., 1987, a new magnetic gear using permanent magnet. IEEE Trans on Magn, 23(5): 3622-3624.

[10] Yousefpoor, N., Fathi, S. H., Farokhnia, N. H., \&Abyaneh, A., 2012, THD minimization applied directly on the line-to-line voltage of multilevel inverters. IEEE Trans. Ind. Electron., 59 (1): 373-380. 